\title{
TRANSFORMAÇÕES TECNOLÓGICAS E PERSPECTIVAS PARA A GESTÃO DEMOCRÁTICA DAS POĹTICAS CULTURAIS
}

\author{
TECHNOLOGICAL CHANGE AND PROSPECTS FOR THE DEMOCRATIC MANAGEMENT OF PUBLIC POLICIES \\ TRANSFORMACIONES TECNOLÓGICAS Y PERSPECTIVAS PARA LA GESTIÓN DEMOCRÁTICA DE LAS POLÍTICAS \\ CULTURALES
}

\section{Resumo}

Este ensaio explora as perspectivas colocadas para a gestão democrática das políticas culturais no Brasil pelo conjunto das transformações tecnológicas em torno da computação ubíqua, da mobilidade, da convergência de dispositivos e da ampliação do acesso a dados públicos. Toma como referencial teórico a construção social da tecnologia e explora a interação entre tecnologia e processos sociais. Com base nesses aspectos, as reflexões foram articuladas a partir da exploração das possibilidades de emergência de novos artefatos tecnológicos para a gestão democrática das políticas públicas de cultura. Essas possibilidades são tratadas em dupla perspectiva: da adoção de padrões de uso da tecnologia e também dos processos de produção desses artefatos. 0 artigo explora, com base nos exemplos identificados na literatura e por meio do método de inspeção estruturada de websites, as possibilidades já efetivadas ou ainda potenciais. Estas são levantadas em termos de participação nas decisões de planejamento e gestão das políticas culturais; compartilhamento de dados e informações relacionados à gestão cultural; transparência e controle social na gestão das políticas culturais. Em seguida, aborda a emergência de novos atores e processos de produção de recursos tecnológicos pela sociedade civil. Conclui-se 0 estudo apresentando um conjunto de questões que devem merecer a atenção dos pesquisadores em uma agenda futura de trabalho para aprofundamento dos pontos nele levantados.

Palavras-chave: Governança eletrônica, políticas públicas de cultura, participação cidadã, transparência e accountability, gestão democrática.

José Carlos Vaz - vaz@usp.br

Professor da Universidade de São Paulo, Escola de Artes, Ciências e Humanidades - São Paulo - SP, Brasil

Submetido 19.07.2016. Aprovado 13.01.2017

DOI: http://dx.doi.org/10.12660/cgpc.v22n71.63284 


\begin{abstract}
This essay explores the prospects brought for the democratic management of cultural policies in Brazil by technological changes revolving around ubiquitous computing, mobility, digital convergence and increasing access to public data. It builds on ideas from Social Construction of Technology and explores the interaction between technology and social processes. Based on these ideas, the essay presents reflections about emerging possibilities of new technological artifacts for the democratic management of public cultural policies. These possibilities are studied in two ways. The first concerns the adoption of technology and its usage patterns. The second is related to the production processes of those artifacts. In the former, the paper analyzes the literature and examples from it and from a structured inspection of websites to explore emerging possibilities, either already delivered or potential ones. These possibilities are grouped under the following categories: participation in the management of cultural policies; sharing of data and information related to cultural management; and transparency and social control in the management of cultural policies. In the latter, the paper explores the emergence of new actors and processes of production of technological resources in civil society. The paper concludes by presenting a set of issues that deserve the attention of researchers in future works.
\end{abstract}

Keywords: Electronic governance, cultural public policies, citizen participation, transparency and accountability, democratic public management.

\title{
Resumen
}

Este ensayo explora las perspectivas aplicadas para la gestión democrática de las políticas culturales en Brasil por el conjunto de las transformaciones tecnológicas generadas por la computación ubicua, la movilidad, la convergencia de dispositivos y el acceso ampliado a los datos públicos. Toma como fundamentación teórica la construcción social de la tecnología y explora la interacción entre tecnología y procesos sociales. Con base en estos aspectos, las reflexiones se articularon a partir del aprovechamiento de las posibilidades de surgimiento de nuevos artefactos tecnológicos para la gestión democrática de las políticas culturales. Estas posibilidades se tratan desde una doble perspectiva: desde la perspectiva de la adopción de nuevos estándares de uso de la tecnolog ía y desde la perspectiva de los procesos de producción de los artefactos. En el caso de la adopcion y uso de la tecnología, el trabajo explora, basado en ejemplos identificados en la literatura y por medio del método de inspección estructurada de sitios web, las posibilidades efectivas o potenciales en términos de participación en las decisiones de planificación y gestión de las políticas culturales; el intercambio de datos e información relacionados con la gestión cultural; y la transparencia y el control social en la gestión de las políticas culturales. En la segunda perspectiva, explora el surgimiento de nuevos actores y los procesos de producción de recursos tecnológicos en la sociedad civil. El ensayo concluye con la presentación de un conjunto de cuestiones que merecen la atención de los investigadores en un futuro programa de trabajo para continuar el debate.

Palabras clave: Gobernanza electrónica, políticas públicas culturales, participación ciudadana, transparencia y rendición de cuentas, gestión pública democrática.

\section{INTRODUÇÃO}

Este ensaio explora os potenciais impactos sobre a gestão democrática das políticas culturais causados pelas transformações tecnológicas ligadas à expansão da computação ubíqua. $O$ argumento central é que as consequências sociais e técnicas dessas transformações vão levar ao surgimento de uma nova geração das práticas de governança eletrônica no campo da cultura. $O$ texto explora as formas pelas quais essas mudanças podem contribuir para o aprofun- damento da gestão democrática das políticas culturais. Para ilustrar o argumento, indicam-se práticas já adotadas ou ainda potenciais, mas deduzíveis do processo de adoção dos novos padrões tecnológicos.

O estudo sobre impactos de mudanças tecnológicas na democratização da gestão pública encontra antecedentes desde a virada do século XX para o século XXI, como os estudos de Heeks e Davies (1999) e de Dimaggio et al. (2001). Com a expansão do alcance e uso da internet, passou-se a discutir como 
essa tecnologia, em específico, pode criar novos instrumentos e práticas para a gestão de políticas públicas com a finalidade de ampliar a participação cidadã e o controle social (Vaz, 2005).

A evolução recente da tecnologia da informação ( $\mathrm{Tl}$ ) exige que se repense esses instrumentos e práticas. Um novo contexto tecnológico, baseado na ubiquidade da computação, estabeleceu-se. É marcado pelo alto nível de conectividade, convergência e mobilidade de dispositivos, pela crescente interatividade e ampliação das possibilidades de acesso, pela interoperabilidade e pelo reúso de bases de dados.

Mudanças de tal envergadura trazem novas possibilidades de democratização da gestão de políticas públicas. Sua concretização dependerá da interação entre processos político-sociais e o desenvolvimento dos recursos tecnológicos.

Após essa introdução, a próxima seção apresenta as escolhas teóricas e metodológicas que embasaram este estudo. Seguem-na seções sobre: democratização da gestão cultural no período pós-redemocratização; interação entre novas tecnologias e os processos sociais; novos instrumentos de gestão democrática das políticas culturais; transformações nas práticas de produção e consumo desses instrumentos. Encerra-se com as considerações finais e exploração de futuras oportunidades de pesquisa abertas por esta pesquisa.

\section{REFERENCIAIS E MÉTODOS}

Refletir sobre as transformações tecnológicas e suas interações com os processos políticos e sociais exige um referencial teórico que considere a tecnologia como parte desses processos. Para tanto, o trabalho baseou-se nas ideias de formação social da tecnologia (Social Shaping of Technology - SST) e de Construção Social da Tecnologia (Social Construction of Technology - SCOT). A SST recusa considerar a tecnologia um produto neutro da inventividade humana. Não é, portanto, uma variável autônoma e que deterministicamente influencia a sociedade (Mackenzie \& Wajcman, 2003). Ao contrário, a tecnologia é interpretada como fruto de processos sociais em que os vários atores interagem com suas aspirações e interesses. Nessas interações, a tecnologia é constantemente ressignificada. Sua apropriação pelos atores sociais transforma as práticas, mas também influencia o desenvolvimento da tecnologia. Os autores ligados à SCOT, como Pinch e Bijker (1984), preferem falar não de formação social, mas sim de construção social da tecnologia. Do ponto de vista da SCOT, os processos que levam à consolidação de determinadas tecnologias e respectivos padrões de uso não são considerados tão espontâneos, devendo destacar o papel de atores específicos e grupos com poder considerável sobre o desenvolvimento da tecnologia e sobre sua adoção pela sociedade.

O referencial da formação e construção social da tecnologia é particularmente útil para entender a adoção de recursos de tecnologia nos processos de democratização da gestão. A simples existência de um recurso tecnológico não determina sua adoção pelos governos ou pela sociedade. Para o caso da democratização da gestão das políticas públicas de cultura, as inovações tecnológicas precisam interagir com um processo 
político e social multifacetado. Movimentos e interesses dos atores envolvidos podem apoiar ou contrapor-se à pressão social por maior democratização da gestão dessa política. Ele não é um processo acabado, e a tecnologia é um dos elementos que pode influenciar seu desenvolvimento, mas não é, certamente, o único nem o maior dos fatores.

Consoante com a opção do referencial teórico, buscou-se identificar os impactos potenciais e efetivos do contexto tecnológico emergente. Utilizou-se como objeto central de reflexão a noção de artefato tecnológico, que é central no trabalho de Pinch e Bijker (1984) e outros no campo da SCOT. Importa entender as características e usos dos artefatos produzidos, mas também seu processo de produção, adoção e utilização. Para tanto, adotaram-se duas dimensões de reflexão: (a) os instrumentos de gestão democrática das políticas culturais; (b) as práticas de produção e consumo desses instrumentos.

A primeira dimensão diz respeito aos artefatos propriamente ditos. Procurou-se responder à questão: "Que mudanças nos instrumentos de gestão democrática das políticas culturais tendem a ser produzidas pelo contexto tecnológico emergente?".

Essa questão foi tratada tomando como referencial o que se convencionou denominar e-democracia (Cunha \& Miranda, 2013). Essa escolha implicou deixar à parte do escopo do trabalho as aplicações referentes à administração dos órgãos governamentais e à prestação de serviços aos cidadãos, pelos mesmos autores denominados, respectivamente, e-administração pública e e- -serviços públicos.

Nessa linha, as possibilidades de aplicações de e-democracia para a democratização da gestão de políticas públicas serão tratadas a seguir em três categorias de uso: 1. participação nas decisões de planejamento e gestão; 2. acesso à informação relacionada à gestão e às políticas; 3 . transparência e controle social na gestão das políticas. Não se trata aqui de propor um modelo teórico para a e-democracia, o que exigiria um outro tipo de trabalho. Recorreu-se a categorias de uso já bastante usadas e apresentadas por outros autores (Vaz, 2005; Cunha \& Miranda, 2013).

A segunda dimensão refere-se aos processos sociais e políticos envolvidos na construção social dos instrumentos de gestão democrática da cultura. Buscou-se refletir sobre a questão: "Qual é o potencial transformador do novo contexto tecnológico sobre o papel dos diferentes atores estatais e não estatais no processo de produção e consumo dos instrumentos de gestão democrática da cultura?". Deu-se destaque às possibilidades de iniciativas colaborativas envolvendo governo e sociedade e de rompimento de dicotomias tradicionais, como produtor-usuário ou emissor-receptor de informações.

Para cada dimensão, buscou-se identificar as possibilidades emergentes, a partir do novo contexto tecnológico e dos processos sociais a ele associados. Nem todas as possibilidades, embora plausíveis, têm experiências de implantação. Assim, foi necessário deduzi-las, a partir das consequências do desenvolvimento dos aparatos tecnológicos e seus padrões de uso mais gerais ou de experiências em outros campos. Entendeu-se que o caráter ensaístico dado ao trabalho auxiliaria 
esse processo por permitir trabalhar mais facilmente com insights para o entendimento das possibilidades de novas práticas de gestão democrática das políticas culturais. Essa abordagem também auxiliou a levantar novas oportunidades de pesquisa sobre o tema.

Para reforçar as reflexões construídas, foram apresentados exemplos de aplicação, em caso de pertinência. Em sua maioria, eles foram extraídos de iniciativas do Ministério da Cultura (MinC) no período 2003-2015. Tomou-se o Ministério da Cultura como referência não somente por ser o mais importante órgão governamental no campo da cultura, mas também por seu reconhecido protagonismo na utilização inovadora de TI (Costa, 2011; Germani, 2016).

Os exemplos do MinC foram obtidos utilizando-se o método de inspeção estruturada de seus portais na internet, que é um recurso de pesquisa amplamente utilizado em estudos sobre o uso de tecnologias nas políticas públicas (Pinho, 2008; Karkin \& Janssen, 2014). Um conjunto de portais e websites (no caso, aqueles relacionados ao $\mathrm{MinC}$ ) é submetido à análise de seu conteúdo para verificar a presença de quesitos de análise predefinidos. Os quesitos analisados corresponderam à presença de recursos de e-democracia, de acordo com as três categorias apontadas antes.

Observe-se que não é objetivo deste estudo prover uma pesquisa exaustiva sobre o uso de TI na democratização da gestão das políticas culturais pelo Ministério da Cultura ou por outras organizações governamentais brasileiras. A pertinência de tal iniciativa é inegável, e este trabalho contribui para a estruturação de uma agenda de pesquisas nessa direção, a partir da reflexão em torno do seu argumento central.

Da mesma maneira, o ensaio não pretende resumir a produção bibliográfica nas várias áreas pelas quais é preciso passar para tratar seu objeto, como políticas culturais, gestão democrática da cultura, governança eletrônica, e-democracia, participação digital, Web 3.0, computação ubíqua, ativismo digital, dados governamentais abertos, redes sociais, big data e construção social da tecnologia. Assim, fez-se a articulação de textos de referência e de textos atuais para apresentar os processos sociais e tecnológicos emergentes e seu potencial de transformação dos padrões de gestão democrática das políticas culturais.

\section{A DEMOCRATIZAÇÃO DA GESTÃO CUL- TURAL NO BRASIL}

As possibilidades de articulação entre democracia e cultura no Brasil torna-se objeto de debate no meio cultural a partir dos anos 1980, em busca de mudança no padrão de atuação do Estado na cultura, marcado pela tradição autoritária e pela postura centralizadora do Executivo apontada por Rubim (2013). Não é objetivo deste estudo refazer esse debate, mas é importante apresentar de forma resumida sua trajetória.

A origem do debate parte da ideia de democratização do acesso à cultura. Tal ideia foi entendida inicialmente como acesso aos bens culturais e artísticos socialmente legitimados pelos setores portadores dos recursos simbólicos para estabelecer as clivagens entre as várias expressões. 
Com a redemocratização pós-1988 e as novas experiências de gestão cultural que floresciam em vários municípios, a democratização do acesso à cultura, estabelecida como centralidade das políticas públicas, passou a ser vista como insuficiente. Segundo Faria (1993, p. 12):

Agora já não basta o cidadão ter acesso à Cultura, mas há necessidade de promover processos de participação para que o cidadão seja agente da sua cultura, deflagrando um ato permanente de criação.

O entendimento da imbricação entre cultura e democracia levou à construção do conceito de democracia cultural, incorporando outros componentes, como a promoção e o respeito à diversidade cultural (Lopes, 2007). Indo mais adiante, as ideias em torno da democracia cultural orientam-se pela concepção de que a democracia cultural deve ultrapassar também os limites da fruição e produção e atingir todas as fases do fazer cultural nas políticas públicas. Isso implica a adoção de práticas democráticas de gestão das políticas públicas de cultura.

Nesse sentido, podem ser apontados quatro direitos que devem ser atendidos pela gestão democrática da cultura voltada a promover a cidadania cultural (Chauí, 1993): direito à informação, direito à fruição, direito à produção e direito à participação.

Com a redemocratização, surgiram diversas experiências de democratização da gestão cultural, as quais se fizeram especialmente presentes nos municípios, a partir da virada das décadas de 1980 para 1990 (Faria, 1993). Dentro de um quadro de experimentalismo difuso, essas iniciativas propuseram a incorporação de expressões e atores sociais antes marginalizados por políticas culturais concentradas na "arte estabelecida" e nas práticas de gestão top-down. Entrou em pauta, também, a superação de práticas autoritárias, elitistas ou burocráticas de gestão cultural.

A partir da década de 2000 , esse processo atingiu também o governo federal (Calabre, 2014), com a elaboração do Plano Nacional de Cultura e a realização da I Conferência Nacional de Cultura, que teve etapas municipais e estaduais, com participação da sociedade civil (Silva, 2014).

Essas práticas de gestão democrática geraram instâncias permanentes de participação, diálogo e controle social, como conselhos de cultura, câmaras temáticas e portais na internet. Iniciativas como o Programa Cultura Viva, do Ministério da Cultura, ou o VAI, da Prefeitura de São Paulo passaram a incorporar novos atores culturais menos profissionalizados e inseridos em circuitos antes vistos como periféricos. A atuação em redes de produtores e agentes culturais, incentivada por esse tipo de política, buscou aumentar o protagonismo e a autonomia das organizações e comunidades (Medeiros et al., 2015). A demanda por espaços de gestão democrática das políticas culturais intensificou-se graças à maior abrangência das políticas (Rubim, 2013). Com isso, novos stakeholders foram incorporados às políticas culturais, tornando mais complexo o ambiente de debate em torno da sua gestão democrática (Calabre, 2014).

Além disso, instâncias não permanentes também foram utilizadas em contextos específicos: fóruns, audiências públicas, consul- 
tas públicas, conferências.

A democratização da gestão das políticas culturais tem se valido da aplicação de recursos de Tecnologias de Informação e Comunicação (TICs) para a promoção da participação social, transparência e controle social dos governos. Têm sido utilizados recursos baseados na internet especialmente para consultas públicas e transparência das ações governamentais, como é o caso do portal do Ministério da Cultura (www.cultura. gov.br).

Entretanto, boa parte da aplicação das TICs ocorre dentro do marco das práticas tradicionais de uso da tecnologia para a participação, transparência e controle social. Cáceres (2011) aponta que as políticas culturais estão configuradas para entender os usos das TICs apenas de forma vertical. Pode-se afirmar que predomina a utilização de recursos tecnológicos em mão única, configurando-se um "modo broadcasting" de governança eletrônica.

Define-se esse "modo broadcasting" como uma maneira de organizar o uso dos recursos digitais como recursos secundários ou complementares às iniciativas presenciais de relacionamento entre governos e sociedade. Nesse modo, são os agentes estatais que estabelecem os momentos, formatos e conteúdo dos processos participativos e de controle social. Eles se restringem-se a iniciativas governamentais, nas quais a interação e participação nas decisões e no controle social das políticas públicas são mantidas sob controle do Estado. Constitui-se de um padrão de acesso aos direitos à informação, ao controle social e à participação mediado pelo Estado, que oferece os recursos, porém controla seu uso e sua abrangência.

\section{A INTERAÇÃO ENTRE NOVAS TECNOLO- GIAS E OS PROCESSOS SOCIAIS}

Um conjunto de novos recursos tecnológicos, combinado com as práticas sociais a eles imbricadas, traz possibilidades de transformação nesse quadro de uso das TICs para a gestão democrática das políticas culturais.

Não é possível predizer quais serão os desdobramentos da evolução dos aparatos tecnológicos envolvidos, nem é possível afirmar categoricamente o quanto e como vão transformar práticas sociais específicas. Segundo Mackenzie e Wajcman (2003), essa evolução ocorre por um processo complexo de intercausalidade envolvendo os aspectos tecnológicos e sociais. O desenvolvimento dos aparatos tecnológicos não pode ser visto isoladamente de sua apropriação pela sociedade, que também os transforma, pela evolução de aplicações e padrões de utilização. Portanto é necessário interpretar esses processos como formação social da tecnologia. Atores com maior capacidade de pressionar ou tomar decisões sobre o curso da evolução dos artefatos tecnológicos e dos padrões de seu uso pela sociedade podem ter um papel destacado em vários desses processos (Pinch \& Bijker, 1984).

A tecnologia e sua apropriação pela sociedade não é, portanto, uma onda inelutável. Assim sendo, não é viável predizer as transformações nas práticas de gestão democrática das políticas culturais por conta das mudanças tecnológicas em curso. No entanto, é possível levantar algumas possibilidades. Antes disso, é importante sistematizar, de 
forma breve, essas transformações no contexto tecnológico. Newman et al. (2016) caracterizam esse contexto pela emergência da chamada Web 3.0, com a convergência de tecnologias como computação em nuvem, Big Data, internet das coisas, redes sociais e segurança de dados junto a recursos já consolidados na internet tradicional.

A disseminação do uso dos dispositivos eletrônicos, o crescimento de sua conectividade e a convergência digital criaram um fenômeno, já anunciado por Weiser em 1993, chamado "computação ubíqua", em que as aplicações da tecnologia da informação penetrariam nas mais variadas atividades humanas, muitas vezes de maneira não perceptível ao usuário (Weiser, 1993).

Esses desenvolvimentos tecnológicos, baseados na redução sistemática dos custos unitários de processamento, armazenamento e transmissão de dados, levaram à emergência de um padrão de uso da tecnologia caracterizado pela computação ubíqua, onipresença de rede e da internet, pela computação e pelo armazenamento em nuvem. Grandes massas de dados passaram a ser armazenados remotamente em relação aos usuários, podendo vir a ter seu uso compartilhado e simultâneo, a baixo custo, por meio da internet. Segundo Rudman e Bruwer (2016), a tendência é a de que as barreiras de formatos de dados e de configurações de redes sejam quebradas, possibilitando que qualquer formato de dado seja compartilhado por qualquer rede e compreendido por qualquer tipo de dispositivo.

Esses recursos tecnológicos reduziram as barreiras ao desenvolvimento de novas aplicações e à entrada de novos atores em mercados e arenas políticas (Newman et. al, 2016). Conforme notado por Santaella (2012): "O computador passa a ser simplesmente uma plataforma de acesso às aplicações, que estariam em uma grande nuvem - a internet".

O surgimento de dispositivos de grande portabilidade e de interfaces com recursos interativos (desde os primeiros portais às redes sociais) adicionou os componentes da mobilidade e da interatividade aos padrões de uso de aparatos eletrônicos fundamentados na internet. A proliferação das possibilidades de contectar à internet recursos de monitoramento de pessoas, objetos, comportamentos e fenômenos por meio de sensores ou de smartphones amplia as possibilidades de conexão, captura de dados e organização de informações (Newman et al., 2016). Configurou-se o que Santaella (2012) denominou tecnologias comunicacionais da conexão contínua: uma rede móvel de pessoas e de tecnologias nômades que operam em espaços físicos não contíguos.

A possibilidade de acessos múltiplos aos dados e as capacidades expandidas de integração de sistemas tanto alimentaram quanto resultaram da expansão do uso de padrões abertos de armazenamento e transmissão de dados. O desenvolvimento tecnológico é concomitante com a expansão da cultura digital livre e resultou em novas práticas de abertura de dados governamentais (Vaz, Ribeiro \& Matheus, 2010) e evolução compartilhada e descentralizada de aplicações de tecnologia.

O desenvolvimento dos aparatos tecnológicos associou-se ao surgimento de novos padrões de apropriação e mudanças na cultura 
de uso da tecnologia, respaldados em novos padrões cognitivos quanto à interação com sistemas e dispositivos. Essas transformações não ocorrem apenas no nível do indivíduo, mas associam-se também a novas formas de relacionamento e de intervenção dos atores sociais e a novas práticas democráticas (Subirats, 2011). No campo da democratização da gestão das políticas públicas, deve-se notar o ativismo digital, caracterizado por iniciativas e grupos que atuam a partir de plataformas digitais. Esse movimento é alimentado pela expansão da infraestrutura e, simultaneamente, estimula o surgimento de novos artefatos informacionais (Scholz, 2010). No campo das políticas culturais, o ativismo digital vem associado à expansão da cultura digital livre (Bakardjieva et al., 2012).

O quadro de transformações tecnológicas e a sua interação com os processos sociais permitem que se considere a emergência de uma segunda geração da governança eletrônica. Supera-se o modo broadcasting de governança eletrônica: quebra-se o monopólio do Estado sobre as decisões e iniciativas de transparência e participação nas políticas públicas. Surgem outras formas de promover a participação, a transparência e o controle social das políticas públicas. As práticas de desenvolvimento compartilhado e os dados governamentais abertos permitem a coprodução e a produção descentralizadas de aplicações e serviços de base tecnológica. Nesse contexto, a sociedade civil e o setor privado podem passar a apropriar-se de dados públicos para produzir novas informações e serviços. Isso significa que podem emergir, desvinculadamente dos governos, formas de participação e intervenção nas decisões das políticas públicas baseadas na tecnologia.

\section{ARTEFATOS E SEUS USOS: OPORTUNI- DADES PARA NOVOS INSTRUMENTOS DE GESTÃO DEMOCRÁTICA DAS POLÍTI- CAS CULTURAIS}

A efetivação do quadro apresentado na seção anterior pode vir a ter implicações expressivas no processo de democratização da gestão das políticas culturais ao longo dos próximos anos. Para explorar essas oportunidades e tendências, entendeu-se ser oportuno utilizar como referência as três categorias de aplicações apresentadas anteriormente: participação nas decisões; acesso à informação e controle social da gestão pública. A seguir, são apontadas as oportunidades de cada uma das categorias, inclusive com indicação de algumas iniciativas que permitem antever, em alguns casos, a materialização das tendências.

Participação nas decisões de planejamento e gestão das políticas culturais

A adoção de práticas participativas nas decisões de planejamento e gestão das políticas é difundida no setor de cultura, ainda que sua exploração ocorra em níveis variáveis de profundidade e não seja necessariamente empregada em todas as situações (Moreira \& Faria, 2005). As TICs são adotadas como instrumento complementar para a promoção da participação na gestão cultural, fortemente baseada em mecanismos presenciais, como fóruns, conferências e consultas públicas.

As experiências emergentes e as possibilidades abertas pelas transformações tecnológicas apontam novas possibilidades. As 
tecnologias e os padrões de seu uso baseados na mobilidade e interatividade oferecem recursos alternativos à participação presencial. A disseminação dos smartphones e da conexão à internet de banda larga passam a permitir a realização de discussões com agilidade. (Stieglitz \& Brockmann, 2013). Criam-se condições para que grandes massas de cidadãos possam contribuir para discussões e decisões sobre as políticas de cultura de forma rápida e quase imediata, apenas respondendo a convocações recebidas diretamente em aplicativos instalados em seus smartphones.

Um exemplo dessas possibilidades são os processos participativos digitais promovidos pelo Ministério da Cultura, inclusive por meio de uma Conferência Nacional de Cultura Virtual, como parte da III Conferência Nacional de Cultura, em 2013 (http://cncvirtual.culturadigital.br).

Outra possibilidade, que já se faz evidente, é a passagem de momentos pontuais de consulta para plataformas permanentes de participação. Pode-se definir esse tipo de recurso como um conjunto de funcionalidades virtuais articuladas entre si e estruturadas para ofertar possibilidades de interação multidirecional e com agenda não restrita à iniciativa governamental. Plataformas permanentes de participação permitem que cidadãos ou organizações se cadastrem e proponham temas, articulados em grupos de discussão, e opinem sobre temas debatidos. O MinC desenvolveu uma plataforma própria, que foi utilizada não somente para suas atividades, mas também por iniciativas de outros ministérios, como a discussão do Marco Civil da internet proposta pelo Ministério da Justiça, em 2009 e 2010 (Stefani,
2015).

Além disso, o governo federal, por meio de plataformas, como Participa.br (www.participa.br) e Dialoga Brasil (www.dialoga.gov.br), criou plataformas permanentes nas quais políticas públicas de cultura são objeto de discussão, entre outras.

Outra oportunidade está presente nas redes sociais, já uma tecnologia amplamente difundida e também operada com base em dispositivos de alta mobilidade. Permite novas formas de interação entre a sociedade e os órgãos públicos responsáveis pelas políticas de cultura. O Ministério da Cultura e várias outras secretarias estaduais e municipais, além de outras organizações públicas no campo da cultura, apresentam perfil em várias redes sociais (FaceBook, YouTube, Twitter, Instagram), utilizados para disseminação de informações e interação com cidadãos.

Cáceres (2011) aponta a dificuldade de sistematizar os padrões de utilização desses recursos no campo das políticas culturais, mas salienta o caráter ainda restrito de sua aplicação. É de se supor que, gradualmente, os padrões de uso das redes sociais na gestão democrática da cultura migrem do modo broadcasting e de interações do tipo pergunta/resposta para um padrão multidirecional e com um nível maior de interação.

Tanto as plataformas permanentes de participação quanto as redes sociais permitem construir conhecimento sobre a opinião pública, por meio de mecanismos de mineração dos conteúdos produzidos pelos usuários (Sobkowicz et al., 2012). Esse conhecimento pode ser apropriado tanto pelo governo quanto pela sociedade, realimentando os 
processos participativos.

Acesso a dados e informações relacionadas à política cultural

As transformações tecnológicas abrem novos espaços para compartilhamento de dados e informações por reduzirem ou eliminarem barreiras técnicas tradicionais. $\mathrm{A}$ primeira barreira é necessidade de acesso físico às bases de dados. Com as tecnologias de computação em nuvem e de alto nível de conectividade, dados podem ser acedidos remotamente, deixando de ser utilizados exclusivamente por aqueles que detém o acesso aos dispositivos de armazenamento.

Uma segunda barreira é a capacidade de processamento e armazenamento. Com as tecnologias de computação em nuvem, os dados não precisam ser copiados e armazenados pelos novos usuários, uma vez que passam a ter contato com eles se tiverem acesso remoto para consultá-los e processá-los nos servidores em que originalmente estão armazenados. Mesmo nos casos em que se pode receber cópias de arquivos de dados pela internet, a tendência é a de que dispositivos ordinários sejam plenamente capazes de realizar seu armazenamento e processamento.

Uma terceira barreira diz respeito aos formatos dos dados. A expansão do uso de dados em padrões abertos ou acessíveis elimina ou reduz as restrições de acesso e uso baseadas na necessidade de softwares específicos para processar dados em formato proprietário (Vaz et al., 2010).

A redução ou eliminação dessas barreiras ocorrem com a crescente possibilidade de integração de bases de dados e sistemas de informação. Essa integração pode abranger sistemas e dados de um mesmo órgão público, de órgãos diferentes, inclusive de distintos níveis da federação, e também dados de organizações da sociedade civil e empresas. Removidas as barreiras técnicas, pode-se trabalhar com grandes volumes de dados interligados e provindos de distintas fontes, por meio de tecnologias BOLD (Big Open LInked Data), conforme apresentado por Janssen e Hoven (2015). Essa tendência, levada ao ambiente da internet, fará com que a compreensão e o tratamento de dados pelas máquinas aproximem-se de uma maneira similar à humana, de acordo com Rudman e Bruwer (2016). Com isso, as capacidades de disponibilização de conhecimento e informação alargam-se significativamente.

Além da superação de barreiras técnicas, a nova conjuntura tecnológica acompanha os padrões e cultura de uso de dados com base nas possibilidades apontadas anteriormente. Abrem-se espaços para novas demandas da parte da sociedade para acesso aos dados e informações em formato legível por máquina. O movimento se retroalimenta, com as ferramentas tecnológicas interagindo com a demanda que, por sua vez, estimula o desenvolvimento da tecnologia e amplia as possiblidades de acesso aos dados e informações (Janssen et al., 2012).

Segundo O'Reilly (2011), o governo deve implantar infraestruturas informacionais que possibilitem a sistemática reutilização de suas informações pela sociedade. Isso cria condições para o surgimento de novas aplicações a partir da própria sociedade. Por 
sua vez, são acolhidas por essas infraestruturas, que as realimentam. Trata-se do chamado governo como plataforma.

A constituição de plataformas desse tipo, com base em padrões abertos de estruturação das bases de dados, permite que múltiplos usuários acessem os dados. Também dá condições para que distintas organizações sirvam-se da plataforma para ofertar acesso a seus dados, uma vez que a plataforma oferece uma camada básica que permite o armazenamento, o processamento e a transmissão de dados que sigam os padrões abertos de estruturação. Com isso, dados oriundos de diferentes organizações e sistemas podem ser disponibilizados por um mesmo recurso, e novas aplicações construídas a partir das camadas básicas de infraestrutura e de interface de acesso e visualização dos dados.

Podem-se, aqui, registrar iniciativas como o Sistema Nacional de Informações e Indicadores Culturais, do Ministério da Cultura (http://sniic.cultura.gov.br). Essa iniciativa indica o potencial da criação de plataformas de disponibilização de informações, dados e indicadores sobre políticas culturais, tornando disponíveis para a sociedade séries históricas sobre as políticas culturais (Rubim, 2013).

Essa mesma ideia de plataforma, como infraestrutura e interface, pode também abrigar recursos de estruturação e visualização de dados e de informações georreferenciadas, uma vez que isso permite a construção de mapas que os representem do ponto de vista espacial. Os mapas tanto podem ser estáticos (por exemplo, mapas com equipamentos culturais, pontos de cultura etc.) ou dinâmicos (mapeamentos culturais colaborativos em base referenciada). Como exemplo, pode-se apresentar a iniciativa Mapa da Cultura, do Ministério da Cultura (http:// mapas.cultura.gov.br). Alguns estados (Ceará e Rio Grande do Sul) e municípios (Blumenau, Santo André, São Paulo e São José dos Campos) também utilizam esse tipo de recurso.

A utilização de plataformas de disponibilização de informações, dados e indicadores sobre políticas culturais propicia que a produção e circulação desses recursos informacionais se conforme como uma via de múltiplos sentidos, quebrando o monopólio do Estado de organizar e produzir informação relacionada à gestão da política de cultura. Isto é possível porque as plataformas podem ser estruturadas de maneira a promover a coleta e sistematização permanente de dados gerados pelos próprios produtores culturais e usuários dos serviços culturais. Esses dados podem ser alimentados de forma totalmente voluntária (por exemplo, pelo cadastro voluntário de produtores culturais) e de forma induzida pelo cruzamento, como a oferta de serviços (por exemplo: oferecimento de recursos de divulgação de atividades e produtores culturais cadastradas na plataforma) ou fornecidos compulsoriamente (por exemplo: requisito para a participação em editais ou para o acesso a outras formas de recursos).

Transparência e controle social na gestão das políticas culturais

As transformações em torno do uso e circulação de dados, apresentadas anteriormente, permitem o surgimento de práticas de publicação de dados que rompem com o tradicional modo broadcasting, no qual o Estado 
detém o monopólio dos formatos, dos meios e dos conteúdos. Plataformas de publicação de dados e informação, como as descritas antes, podem também ser utilizadas para efeitos de transparência e controle social.

No entanto, é na adoção de recursos de publicação de dados governamentais abertos que parece existir maior possibilidade de inovação na promoção da transparência e do controle social. Entendemos aqui dados abertos como dados originados do governo que se tornam disponíveis para a sociedade pela internet, em formato bruto, aberto $e$ compreensível por máquinas, visando à sua reutilização. Araújo e Souza (2011) afirmam que os dados governamentais abertos possibilitam o aumento da transparência do governo.

No caso das políticas culturais, isso permite que se possa receber pela internet conjuntos de dados que propiciam o acompanhamento de temas, como o financiamento de iniciativas culturais, a alocação de recursos, o cruzamento de dados de beneficiários de políticas e as leis de incentivo. Entre as iniciativas já existentes, pode-se apontar a publicação de indicadores relativos à concessão de incentivo fiscal para projetos culturais por intermédio da Lei Rouanet no portal dados.gov.br (http://dados.gov.br/dataset/ incentivo-fiscal-para-projetos-culturais).

A transparência e o controle social das decisões nas políticas culturais também podem ocorrer por meio da implantação de recursos de transparência do funcionamento e desempenho de sistemas e processos (Vaz, 2005). Tal emprego da tecnologia pode ocorrer pela divulgação do andamento de solicitações da sociedade e das ações tomadas pelos dirigentes públicos. Para que tal resultado seja atingido, é preciso que os recursos eletrônicos empregados voltem-se não apenas para o processamento das demandas, mas também para a maior interação dos cidadãos, além de prover recursos de publicidade das ações do sistema. A arquitetura de sistemas, nesse caso, deveria considerar recursos de ordenamento e publicidade de atendimento permitindo perceber, por exemplo, se as solicitações estão sendo atendidas em ordem cronológica. Apesar da disponibilidade de tecnologia para tanto, ainda é um recurso pouco utilizado.

O uso de dados governamentais abertos, redes sociais, dados coletados de aplicativos móveis ou sensores e plataformas permanentes de divulgação de informações e de participação também ampliam as possibilidades em termos de avaliação das políticas culturais.

É possível conceber processos coletivos e abertos de avaliação, não restritos à participação presencial. Com maior disponibilidade e acesso a dados, a sociedade pode valer-se deles para produzir suas próprias análises, ampliando sua capacidade de participar nas avaliações (Vaz et al., 2010; Attard et al., 2015).

No nível dos serviços, também é possível ampliar possibilidades de participação dos cidadãos na sua avaliação. Os recursos de acesso e processamento de dados usando a tecnologia de computação em nuvem, combinados com as tecnologias de dispositivos móveis, podem permitir o desenvolvimento de aplicativos de microavaliação de experiência. Esses aplicativos utilizam-se do princípio do mobile crowdsourcing, com 
base na coleta de dados produzidos e transmitidos pelos próprios usuários pelos dispositivos móveis (Salim e Haque, 2015), como dados de localização de smartphones.

Com isso, é possível coletar grande volume de dados de usuários de equipamentos e serviços vinculados à política de cultura. Os dados a coletar podem ser relativos à localização e utilização (por exemplo, coletar tempos de permanência em equipamentos ou atividades). Em outra vertente, coleta de dados vinculados à sua opinião ou a avaliações de reação no contexto imediato de acesso e usufruto dos equipamentos e serviços. Apesar dessas possibilidades, sua utilização ainda é muito restrita.

\section{COMO SE PRODUZEM OS ARTEFATOS: TRANSFORMAÇÕES NA PRÁTICA DE PRODUÇÃO DE INSTRUMENTOS DE GESTÃO DEMOCRÁTICA DA CULTURA}

Como já apresentado, o desenvolvimento tecnológico e sua contrapartida em termos de modos de apropriação da tecnologia criam espaço para a coprodução e a produção descentralizadas de aplicações e serviços de base tecnológica, com a sociedade civil e o setor privado apropriando-se de dados públicos para produzir novas informações e serviços.

Pinho (2011) afirma que a internet reduz a importância de intermediários e permite o surgimento de instâncias colaborativas e cooperativas de produção. Com isso, abre-se espaço para iniciativas colaborativas envolvendo governo e sociedade.

É possível vislumbrar o desenvolvimento compartilhado de aplicativos para demo- cratização da gestão e de prestação de serviços, em itens como o acesso a agendas culturais, aplicativos de apoio à fruição de acervos e equipamentos ou aplicativos de relacionamento entre governos, empresas e produtores culturais.

Outra possibilidade aberta são os mapeamentos culturais dinâmicos e participativos. Trata-se de plataformas, integradas ou não a redes sociais e dispositivos móveis, que permitem o cadastramento, a divulgação e a interconexão de atividades, equipamentos e produtores culturais. Em iniciativas como a da Agência Solano Trindade, no município de São Paulo, a política pública criou espaço para que agentes da sociedade civil fossem os construtores e articuladores da plataforma, por exemplo (Sena, 2013).

A lógica desses mapeamentos faz parte de uma transformação que leva ao rompimento da divisão entre produtores e usuários das informações, apontado por Rocha e Pereira (2010). Os usuários assumem o papel de produzir as informações que alimentam o mapeamento, mas também utilizam-se dele para suas necessidades de contato, divulgação e registro de informações.

Essas transformações possibilitadas pela tecnologia tendem a reduzir as dicotomias clássicas, como produtor-usuário e emissor-receptor, pois o grau de interatividade traz fluidez aos limites entre produção e consumo dos artefatos que se constituem instrumentos de gestão democrática da cultura. Ao contrário dos artefatos em suporte analógico dos artefatos digitais em modo broadcasting, os novos instrumentos estão em permanente construção, a qual ocorre pela adição de valor e trabalho tanto por aquele que produz 
o artefato (o desenvolvedor do aplicativo) quanto por seu usuário (que alimenta com dados e modificações o aplicativo).

\section{CONSIDERAÇÕES FINAIS}

As reflexões aqui apresentadas apontam a existência de novas potencialidades para a democratização da gestão das políticas culturais, propiciadas pelo desenvolvimento tecnológico. Os exemplos apontados demonstram a possibilidade concreta de materialização de muitas dessas potencialidades.

Entretanto, a identificação dessas possibilidades e de alguns exemplos já mais ou menos consolidados não significa que, necessariamente, virá um mundo maravilhoso de democracia da gestão das políticas culturais. A disponibilidade material de aparatos tecnológicos não é suficiente para antever seus impactos, pois a tecnologia não existe isolada dos processos sociais.

Muitos recursos tecnológicos têm seu potencial pouco explorado. Assim, refletir sobre os impactos da tecnologia na democratização da gestão das políticas culturais é sempre um trabalho parcial e provisório, uma vez que a evolução dos aparatos tecnológicos e das formas de sua apropriação pela sociedade é um processo dinâmico e dominado por causalidades e intercausalidades complexas.

Com base nisso, é possível constatar que nem todas as possibilidades tecnológicas são igualmente exploradas, o que nos remete a questões específicas sobre a apropriação das tecnologias emergentes pela democratização da gestão cultural. As po- tencialidades identificadas a se materializarem de forma expressiva trarão novos problemas nos seguintes temas: privacidade, segurança e proteção de dados, competências e responsabilidades de órgãos públicos, circulação de informações e formação de gestores culturais, entre outros.

Além dessas questões específicas, algumas outras, de caráter geral, já podem ser propostas. Ainda que não se pretenda explorá-las em profundidade neste estudo, nem produzir uma lista completa, é possível identificar, desde já, algumas delas.

Uma primeira indagação diz respeito à diferença entre o ritmo da gestão das políticas públicas e o da evolução dos aparatos tecnológicos e de seus padrões de uso pela sociedade. Será que os governos conseguirão acompanhar o ritmo da mudança social e tecnológica em curso? Isso nos faz pensar que os governos que se comprometam com a democratização da gestão das políticas culturais devem defrontar-se com as dificuldades advindas das práticas políticas e administrativas do Estado brasileiro. Como já assinalado por Diniz et al. (2009), fatores políticos, institucionais e técnicos combinam-se para a materialização das políticas de uso da tecnologia pelos governos. Aspectos como a dinâmica do sistema político sobre o funcionamento do Estado, a prevalência da lógica burocrática ou a hipertrofia dos aparatos de controle interno e externo da administração pública merecem ser considerados. Futuras pesquisas podem identificar as relações entre esses aspectos e a adoção da tecnologia para a democratização da gestão das políticas culturais. Colocam-se questões como a intercausalidade, os fatores que influenciam os processos de adoção 
José Carlos Vaz

da tecnologia e os impactos dos novos instrumentos.

Uma segunda questão é decorrente das considerações citadas. O Estado será capaz de estimular e aproveitar as iniciativas da própria sociedade que contribuam para a democratização da gestão das políticas culturais? Isso significaria voltar a ação dos órgãos públicos que atuam no campo cultural para novas formas de trabalhar, nas quais os resultados não mais dependem exclusivamente de seu controle. Entender como o Estado será capaz de construir ou ativar capacidades para essas novas demandas é uma questão de pesquisa relevante, dado que, historicamente, o Estado brasileiro mostra fragilidades em termos de capacidades para a gestão das políticas culturais (Rubim, 2013).

Como mostra Tsagarousianou (1998), essa é, necessariamente, uma via de mão dupla. Portanto, será preciso considerar também os padrões de relacionamento entre a sociedade e o Estado e as dinâmicas internas dos vários campos e atores da sociedade.

Sandoval-Almazan e Gil-Garcia (2014) mostram que as estratégias da sociedade civil são constantemente modificadas pelos processos políticos, sociais e tecnológicos. É de supor que o surgimento de novos usos da tecnologia pela sociedade não se comporte de maneira linear e que seja altamente influenciado pelos contextos específicos. Compreender as situações particulares e os processos nelas envolvidos é uma necessidade que deve ser considerada em uma agenda futura de pesquisa sobre o tema. Essas pesquisas podem evoluir do estudo de casos singulares para esforços de gene- ralização.

Para esse esforço, pode-se vislumbrar questões de duas naturezas. Inicialmente, é possível perguntar até que ponto essas configurações são específicas ao campo das políticas de cultura, ou alinham-se a tendências gerais. Ou, dito de outra maneira, cabe aprofundar as especificidades da cultura na aplicação de tecnologias para a democratização da gestão de políticas públicas.

Em segundo lugar, o referencial da construção social da tecnologia nos mostra que os atores e seus interesses representam um elemento importante nos processos de adoção da tecnologia. Como visto antes, o campo das políticas culturais envolve uma multiplicidade de atores, e há o desafio de interpretar os processos de envolvimento desses atores na produção dos instrumentos tecnológicos de democratização da gestão cultural. Araújo et al. (2015) apontam evidências de que as organizações da sociedade civil tendem a obter melhores resultados a partir do "uso criativo das ferramentas digitais e, principalmente, pela capacidade de conexão entre o ativismo virtual e presencial". Estudos sobre as práticas dos atores da sociedade civil e suas estratégias são necessários para entender as dinâmicas de adoção da tecnologia.

Nesse mesmo tema, merecem interesse as seguintes questões: a centralidade ou não do Estado; o papel dos intermediários informacionais; as articulações entre atores distintos em torno da tecnologia; os processos de coprodução de serviços digitais, e a emergência de uma esfera pública digital no campo da democratização da gestão cultural. 
Por fim, é inevitável perguntar se ocorrerá uma apropriação desigual dos desenvolvimentos tecnológicos aplicados à gestão das políticas culturais. Em um contexto de desigualdade e apropriação excludente da tecnologia, esse risco não pode ser desprezado. Estudos de caso serão bastante oportunos para entender se atores com maior poder e acesso a recursos estariam em melhores condições de tirar proveito de mecanismos de democratização, excluindo ou marginalizando outros. Governos sem nenhum compromisso com a democratização da cultura, ou mesmo com a defesa da política cultural como política pública estratégica, podem negar-se a utilizar tecnologias que democratizem a gestão, ou valer-se delas como arremedo, apenas para legitimar seu poder. Não seria a primeira vez, na história brasileira, em que novas possibilidades democráticas seriam capturadas por setores minoritários dispostos a exercer a democracia a seu modo.

\section{REFERÊNCIAS}

Araújo, L. R., Souza, \& J. F. (2011). Aumentando a transparência do governo por meio da transformação de dados governamentais abertos em dados ligados. RESI-Revista Eletrônica de Sistemas de Informação, 10(1), 1-15.

Araujo, R. P. A., Penteado, C. L. C., \& Santos, M. B. P. (2015). Democracia digital e experiências de e-participação: Webativismo e políticas públicas. História, Ciências, Saúde-Manguinhos, 22(suppl.), 1597-1619. doi:10.1590/S0104-59702015000500004

Attard, J., Orlandi, F., Scerri, S., \& Auer, S. (2015). A systematic review of open gover- nment data initiatives. Government Information Quarterly, 32(4), 399-418. doi:10.1016/j. giq.2015.07.006

Bakardjieva, M., Svensson, J., \& Skoric, M. (2012). Digital citizenship and activism: Questions of power and participation online. JeDEM-eJournal of eDemocracy and Open Government, 4(1), 1-4.

Cáceres, J. G. (2011). Las nuevas tecnologías de información y comunicación y las políticas culturales en México: Ingeniería en Comunicación Social del servicio de redes sociales Facebook. Intercom: Revista Brasileira de Ciências da Comunicação, 34(2), 175-196. doi:10.1590/S1809-58442011000200010

Calabre, L. (2014). Política cultura em tempo de democracia: A era Lula. Revista do Instituto de Estudos Brasileiros, (58), 137-156. doi:10.11606/issn.2316-901X.v0i58p137-156

Chauí, M. (1993). São Paulo - uma opção radical e moderna: Democracia cultural. Revista Pólis, 12, 9-38.

Cunha, M. A. C., \& Miranda, P. R. M. (2013). $O$ uso de TIC pelos governos: Uma proposta de agenda de pesquisa a partir da produção acadêmica e da prática nacional. O\&S - Organizações e Sociedade, 20(66), 543-566. doi:10.1590/S1984-92302013000300010

Costa, E. S. (2011). Com quantos gigabytes se faz uma jangada, um barco que veleje: $O$ Ministério da Cultura, na gestão Gilberto Gil, diante do cenário das redes e tecnologias digitais. Rio de Janeiro: Fundação Getulio Vargas - Centro de Pesquisa e Documentação de História Contemporânea do Brasil - CPDOC - Mestrado Profissional em Bens 
Culturais e Projetos Sociais. (Dissertação de Mestrado).

Dimaggio, P., Hargittai, E., Neuman, W. R., \& Robinson, J. P. (2001). Social Implications of the internet. Annual Review of Sociology, 27, 307-336. doi:10.1146/annurev.soc.27.1.307

Diniz, E. H., Barbosa, A. F., Junqueira, A. R. B., \& Prado, O. (2009). O governo eletrônico no Brasil: Perspectiva histórica a partir de um modelo estruturado de análise. RAP-Revista de Administração Pública, 43(1), 2348. doi:10.1590/S0034-76122009000100003

Faria, H. J. B. (1993). Os sentidos da cultura nas cidades. Revista Pólis, 12, 3-8.

Germani, L. B. (2016). Desafios para o desenvolvimento de serviços digitais pelo governo federal brasileiro. São Paulo: Pontifícia Universidade Católica de São Paulo (Dissertação de mestrado).

Heeks, R., \& Davles, A. (1999). Different approaches to information age reform. In: Heeks, R. (Ed.), Reinventing government in the information age: International practice in IT-enabled public sector reform. London: Routledge.

Janssen, M., Charalabidis, Y., \& Zuiderwijk, A. (2012). Benefits, adoption barriers and myths of open data and open government. ISM-Information Systems Management, 29(4), 258-268. doi:10.1080/10580530.2012 .716740

Janssen, M., \& Hoven, J. d. (2015). Big and Open Linked Data (BOLD). In government: A challenge to transparency and privacy? Government Information Quarterly, 32(4), 363-
368. doi:10.1016/j.giq.2015.11.007

Karkin, P., \& Janssen, M. (2014). Evaluating websites from a public value perspective: $A$ review of Turkish local government websites. International Journal of Information Management, 34(3), 351-363. doi:10.1016/j.jijnfomgt.2013.11.004

Lopes, J. T. (2007). Da democratização à democracia cultural. Uma reflexão sobre políticas culturais e espaço público. Porto: Profedições.

Mackenzie, D., \& Wajcman, J. (2003). The social shapping of technology. Maidenhead, Philadelphia: Open University Press.

Magno, F., \& Cassia, F. (2015). Public administrators' engagement in services co-creation: Factors that foster and hinder organisational learning about citizens. Total Quality Management \& Business Excellence, 26(1112), 1161-1172. doi:10.1080/14783363.2014.9 18706

Medeiros, A. K., Alves, M. A., \& Farah, M. F. S. (2015). Programa Cultura Viva e o campo organizacional da cultura: Análise de políticas públicas pela perspectiva institucionalista. RAP-Revista de Administração Pública, 49(5), 1215-1235. doi:10.1590/00347612130337

Moreira, A. J., \& Faria, H. J. B. (2005). Cultura e governança: Um olhar transversal de futuro para o município. Revista Pólis, 48, 9-18.

Newman, R., Chang, V., Walters, J. \&e Wills, G. B. (2016). Web 2.0 - The past and the future. International Journal of Information Management, 36(4), 591-598. doi:10.1016/j. 
ijinfomgt.2016.03.010

O'reilly, T. (2011). Government as a platform. Innovations, 6(1), 13-40.

Pinch, T. F., \& Bijker, W. E. (1984). The social construction of facts and artifacts: or how the sociology of science and the sociology of technology might benefit each other. In: The social construction of technological systems: New directions of the sociology and history of technology. Cambridge, UK: The MIT Press.

Pinho, J. A. G. (2008). Investigando portais de governo eletrônico de estados no Brasil: muita tecnologia, pouca democracia. RAPRevista de Administração Pública, 42(3), 471-493.

Pinho, J. A. G. (2011). Sociedade da informação, capitalismo e sociedade civil: Reflexões sobre política, internet e democracia na realidade Brasileira. RAE-Revista de Administração de Empresas, 51(1), 98-106. doi:10.1590/S0034-75902011000100009

Rocha, M. C. F., \& Pereira, G. C. (2010). De consumidor a produtor de informação: participação política no contexto da nova cultura tecnológica. Cadernos PPG-AU/UFBA, 9(Edição Especial), 73-86.

Rubim, A. A. A. (2013). Políticas culturais do governo Lula. Revista Lusófona de Estudos Culturais / Lusophone Journal of Cultural Studies. 1(1), 224-242.

Rudman, R., \& Bruwer, R. (2016). Defining Web 3.0: Opportunities and challenges. The Electronic Library, 34(1), 132-154. doi:10.1108/EL-08-2014-0140
Salim, F., \& Haque, U. (2015). Urban computing in the wild: A survey on large scale participation and citizen engagement with ubiquitous computing, cyber physical syste$\mathrm{ms}$, and internet of things. International Journal of Human-Computer Studies, 81, 31-48. doi:10.1016/j.ijhcs.2015.03.003

Sandoval-Almazan, R., \& Gil-Garcia, R. (2014). Towards cyberactivism 2.0? Understanding the use of social media and other information technologies for political activism and social movements. Government Information Quarterly, 31(3), 365-378. doi:10.1016/j. giq.2013.10.016

Santaella, L. (2012). A tecnocultura atual e suas tendências futuras. Signo y Pensamiento, 30(60), 30-43.

Sena, E. A. (2013). Políticas culturais, tecnologias de informação e democracia cultural: O programa VAl e a constituição da Agência Popular Solano Trindade. São Paulo: Escola de Comunicações e Artes, Universidade de São Paulo (Dissertação de mestrado).

Silva, R. M. D. (2014). As políticas culturais brasileiras na contemporaneidade: Mudanças institucionais e modelos de agenciamento. Sociedade e Estado, 29(1), 199-224. doi:10.1590/S0102-69922014000100011

Scholz, T. (2010). Infrastructure: Its transformations and effects on digital activism. In: Joyce, M. (ed.), Digital activism decoded: the new mechanics of change. New York, USA: IDEBATE Press.

Sobkowicz P., Kaschesky M., \& Bouchard G. (2012). Opinion mining in social media: Mo- 
deling, simulating, and forecasting political opinions in the web. Government Information Quarterly, 29(4), 470-479. doi:10.1016/j. giq.2012.06.005

Stefani, A. G. M. (2015). Utilização de TICs em processos participativos no Brasil sob a ótica de capacidades de governo. São Paulo: Programa de Pós-graduação em Gestão de Políticas Públicas, Escola de Artes, Ciências e Humanidades, Universidade de São Paulo (Dissertação de mestrado).

Stieglitz, S., \& Brockmann, T. (2013). The Impact of Smartphones on E-Participation. 46th Hawaii International Conference on System Sciences (HICSS), 1734-1742.

Subirats, J. (2011). Otra sociedad, ¿otra política? De "no nos representan" a la democracia de lo común. Barcelona, Espanha: Icaria Editorial.
Tsagarousianou, R. (1998). Electronic democracy and the public sphere: Opportunities and challenges. In: Tsagarousianou, R., Tambini, D., \& Bryan, C. (ed.). Cyberdemocracy: Technology, cities and civic networks. New York, USA: Routledge.

Vaz, J. C. (2005). Governança eletrônica: Para onde é possível caminhar? Revista Pólis, (número especial), 14-19.

Vaz, J. C., Ribeiro, M. M., \& Matheus, R. (2010). Dados governamentais abertos e seus impactos sobre os conceitos e práticas de transparência no Brasil. Cadernos PPG-AU/UFBA, 9(Edição Especial), 45-62.

Weiser, M. (1993). Ubiquitous computing. Computer, 26(10), 71-72. 